\title{
Some Considerations on the Empirical Research of Goal Systems of Insurance Companies *
}

\author{
by Bernd Kaluza **
}

\section{Introduction}

A discussion of empirical goal research in imsurance companies must refer to the framework of the large discussion concerning empirical goal research per se. Our discussion will be based on a critical analysis of the work that has been done until now in the area of empirical goal research. In this context we will examme the following problems :

- Why should empirical goal research be carried out at all ?

- What are its tasks?

- By what criteria are the results to be judged?

- How far have we progressed in empirical goal research and how far do we still have to go?

- What can be said about the possibilities, empirical goal research can help to develop and about the constraints imposed on empirical goal research ?

Our discussion of these questions will be based on the decision-oriented approach to busmess administration (see Heinen [1980], 22-29) and the empirical theory of the firm (see e.g. Witte [1972 a]) developed in Germany.

\section{Empirical goal research in business administration}

We shall try to review the empirical goal research done until now in business admimistration. Furthermore, we would like to point out the necessity of doing further research in this area.

* This is a revised and condensed version of a paper presented at the 8 th Seminar of the European Group of Risk and Insurance Economists, University of Cologne, September 23-25, 1981.

** University of Mannheim. 


\subsection{Priority areas in empirical goal research}

A theory concerning the goals of business firms should be able to accomplish the following tasks : to describe and examine the process by which goals are formed ; to determine which goals are actually pursued by business firms (analysis concerning the existence of specific goals) ; to explain how and why the existence of certain goals and the processes, by which these goals are formed, are contingent on specific conditions (contingency hypothesis); and to describe the influences that certain goals and certain processes, by which these goals are formed, exert on other phenomena (hypotheses concerning effects) (see Grün [1976], 4719-4730; Hauschildt [1977], 243-260).

Developing a theory such as the one described above has proved to be a very demanding task. So far only certain parts of this theory have been worked on. The priority areas in research for the development of a theory concerning the goals in business firms, that is supported by empirical evidence, are shown in Figure 1.

As can be concluded from this illustration the research to systematically find all goals can, for one, be directed towards understanding the goal orientation of companies (entire business firms). In this case the so-called goals of a business enterprise (corporate goals, organizational goals) are discussed. ${ }^{1}$ Decision goals, on the other hand, do not pertain to the entire business firm, but to single, usually precisely defined decision processes (see Hauschildt [1977], 17-76). A considerable amount of empirical research has already been done concerning this area, especially concerning decision goals pertaining to the procurement of capital goods. ${ }^{2}$

\subsection{Methodology of empirical goal research}

In empirical goal research one must differentiate between research that is directly oriented toward the problem of goals and such that is indirectly oriented toward the problem of goals one examines, for example, decisions concerning the means employed in certain situations and the resulting consequences first. Then one tries to draw conclusions concerning the underlying decisions pertaining goals on the basis of the observed behavior of an entrepreneur (see Heinen [1971], 30-34; Lerchner [1975], 25-27).

In the research that is directly oriented towards the problem of goals one attempts to discover the existence of particular goals in a one-step procedure. The following methods are used in this type of empirical goal research : Interviews, questionnaires, observations, analyses of documents, and experiments (e.g. business games). ${ }^{3}$

In the following we would like to discuss some of these methods, interviews, questionnaires, and analyses of documents, since we used these in our empirical

1 For a more detailed discussion and review on research of empirical goals in business enterprises see Kaluza [1979], 246-292 ; Kupsch [1979], 137-143; Strebel [1981], 462.

2 The explosion of the literature of this subject is documented by Gemünden [1981].

3 See for detailed information Witte [1974], 1264-1281; Hauschildt [1977], 270-297; Kaluza [1979], 238-245; Kupsch [1979], 141-143. 


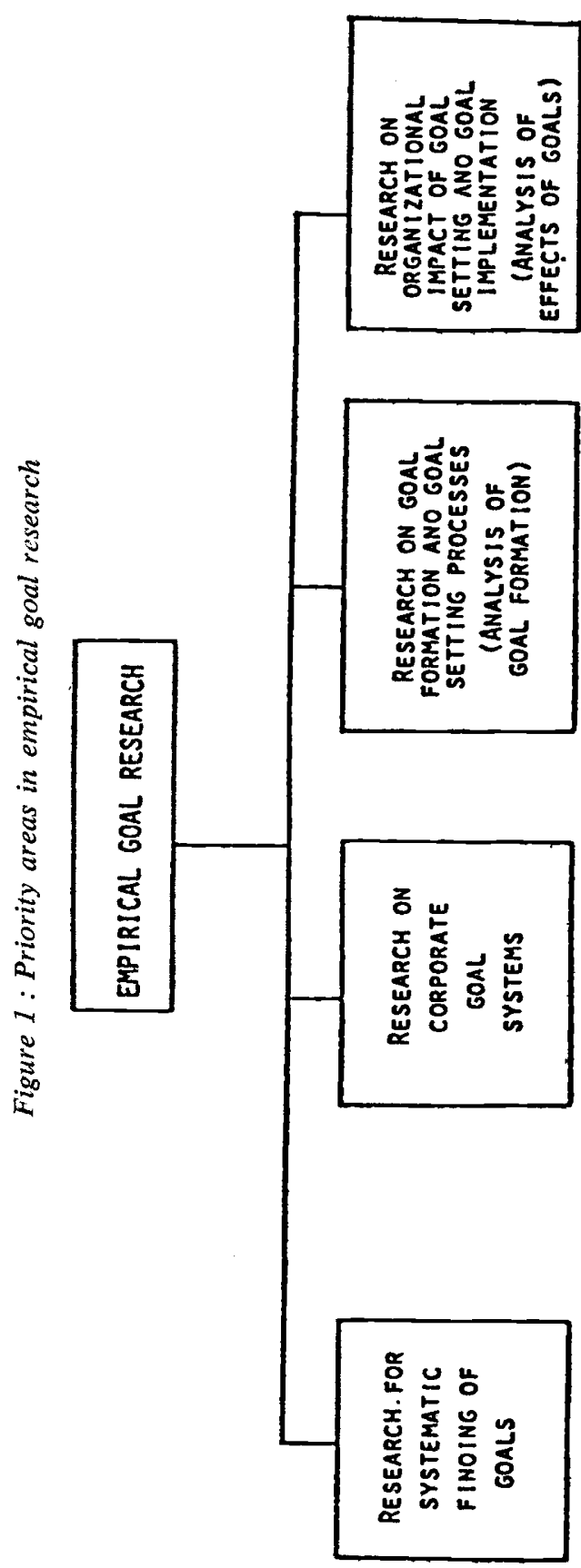


research. Interviews and questionnaires are methods which are not very well suited to determine the goals of a particular firm. It is, for example, by no means certain, that the responses of the persons interviewed concerning goals are backed up by their willingness to act accordingly. 4

In addition there are a number of other problems that are connected to the use of interviews in empirical goal research. These include such items as the type of interview to be used (standardized, structured, or open interviews), the selection of persons to be interviewed, and the willingness and capacity of the selected persons to provide the desired information (see Kaluza [1979], 243).

The analysis of documents on the other hand is one of the methods that is not oriented towards people, but towards objects. ${ }^{5}$ This method encompasses the analyses of the documents of a firm concerning the content with the purpose of identifying the relevant goals. A precondition for employing this method is the availability of documents that could provide this information. Such documents are, for example, the charter of a firm or declarations of principle by top management concerning policy. When analysing these documents, however, one must always consider who is being addressed. This will decide if top management is really expressing its position pertaining to a particular subject area (also, for example, in internal policy papers) or if declarations of intent are being given, which will not be followed up, but are intended to improve a firm's image and are therefore directed at the general public (this is possible, for example, in business reports).

In examining documents such as, for example, charters one must determine to what extent the previously postulated goals differ from the present ideas on this subject and the present way of doing things. Furthermore, one must determine to what extent these documents are relevant for the actual forming of the goals in the firm. It therefore stands to reason, that the relevance of documents can not be judged on the basis of this material. Interviews, questionnaires, and observations are normally also necessary (see Kaluza [1979], 293-296).

A comparison of the studies done in empirical goal research until now shows a clear predominance of interviews and questionnaires. Therefore, when past and present empirical goal research is criticized for being monistic or one-sided concerning the methods that are employed (see Hauschildt/Hamel [1978], 173-186), the author - also on the basis of having analysed further studies - concurs. ${ }^{6}$

In addition to the one-sidedness of the methods that are employed, one must also criticize the one-sidedness in the selection of those that are to be interviewed or questioned. In about 70 per cent of the studies we looked at, only members of top management were considered. The routine of always employing the same methods

4 Some authors consider the goal maintenance of the buying power of the currency, which members of top management often profess to have, to be a goal, to which top managers pay lip-service in order to demonstrate, under pressure from public opinion, their consciousness of their duty to society as a whole. See Szyperski [1975], 247-272. 719-734.

5 For the methodological approach see Hauschildt [1970], 549-559; Hauschildt [1973],

6 See for detailed analysis Kaluza [1979], 246-292. 
and always questioning groups of similar and highranking persons can result in a dangerous situation, in which empirical goal research will be turning in circles, meaning that the finding of always the same propagated goals will be repeated without the really practised goals being found (see Hauschildt/Hamel [1978], 173-186).

\subsection{Results of empirical goal research}

One general result of the many different studies done in empirical goal research has been that all authors have discovered multi-variable goal systems. The formal structure of goal systems is shown in the following Figure 2.

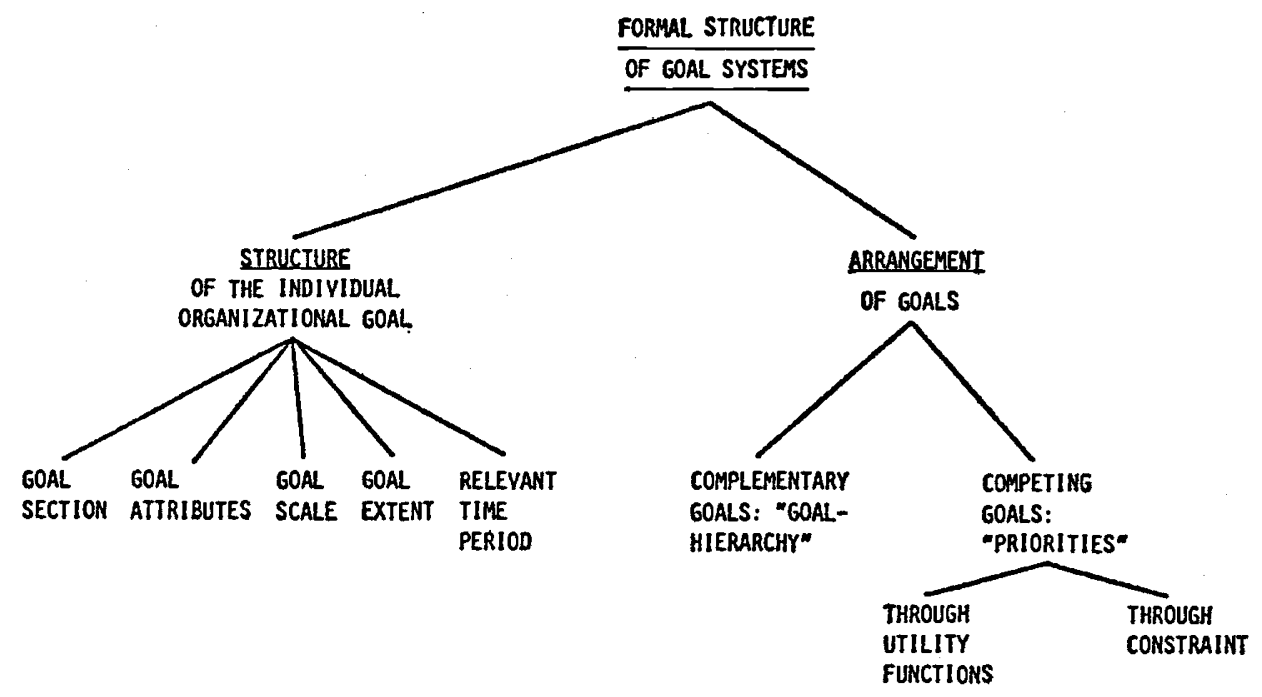

Figure 2 : Formal structure of goal systems

A direct comparison of the different results of the particular studies, however, is not possible, since in some studies the persons interviewed were confronted with the already formulated goals, whereas in other studies the goals were only formulated during the research. It is, however, interesting to note that none of the authors purports to have discovered anywhere near all the different goals. ${ }^{7}$

Only few conclusions concerning the factors relevant to determining the outcome of the processes by which goals are formed - also called the goal search process - in business enterprises have been backed up by empirical research. In this context one must differentiate between external determinants (social norms, values, and political circumstances) and internal determinants (size, legal framework for an organization, industry) (see Grün [1976], $4723+4724$ ).

7 To a detailed information which goals and groups of goals were discovered in certain selected studies see Kaluza [1979], 246-292. 
The individual organizational goals are formed in a process in which ends and means-relationships are given due consideration. This concept which was introduced by Myrdal has a long and honorable tradition in the field of business administration. The systematic development of a hierarchy of goals from the top down (= goal specification) could not be substantiated by Hauschildt with empirical studies. He also could not find empirical evidence to prove that the search for goals, meaning the development of a hierarchy of goals from the bottom up proceeded in this form. Rather, he suspected that the process of developing goals is of a heuristic nature in which hierarchically speaking higher and lower elements of goals are in a constant state of interaction (heuristic of goals) (see Hauschildt [1976], 327-340).

In the following we would also brieflly like to discuss the role the process of goal formation could play as a determinant. In other words we would like to examine how the process of goal formation is involved in changes of a system of goals. One differentiates, among others, between the following types of goal conversions : goal displacement; goal succession; goal change; goal diversification (see Warner/Havens [1967], 539-545; Grün [1976], 4724).

Influences pertaining to the processes of goal formation, meaning the so-called analysis of effects of goals, are especially of interest in research concerning the management by objectives ( $m b o$ )-concept. The hypothesis that the introduction of the mbo-principle into a firm would increase the degree to which goals are attained and stimulate the employees to produce more, has not been proven to be the case in any consistent manner. In studies conducted by Tosy and Caroll the questioned line managers considered the existence of clear expectations concerning behavior to be the most important asset of the mbo-principle (see e.g. Tosy/Caroll [1973], 57-66). Differences concerning the meaning of specific goals, however, were discovered between business enterprises, in which the mbo-concept had been applied and in those, in which it had not. In business enterprises that did not employ the mbo-concept goals were more oriented towards furthering smooth operations, whereas in business enterprises that did employ the mbo-concept goals were more oriented towards specific levels of results. Furthermore, one discovered that in mbo-business enterprises employees consider the standards to which their performances are compared to be not as flexible (see Tosy et al [1976], 276-302; see for mbo and insurance Schulz [1979], 72-75).

The hypothesis concerning effects that is most often tested pertains to the connection between participation and goal acceptance. According to this hypothesis participation in forming goals increases the willingness to attain these goals. ${ }^{8}$

\section{Empirical analysis of the goal systems of insurance companies}

First of all we want to show that empirical goal research in insurance companies is a priority area for research in the theory of insurance business. Secondly, we provide a broad perspective on our study.

8 Höller thoroughly examines the different empirical studies concerned with the subject participation in planning goals and performances. See Höller [1978]. To other studies with similar problems see Latham/Yukl [1975], 824-843. 


\subsection{Empirical goal research in insurance companies as a priority area for research in insurance business administration}

The theory of insurance business administration (abbreviated $i b a$ ) contains considerably less theoretical statements concerning decisions than other types of business administrations dealing with other industries. The insurance industry itself, as well as those concerned with developing insurance business theory (see e.g. Farny [1969], 28-33 ; Karten [1976], 4252) point to these difficulties in iba-research.

In addition to this necessity for further empirical research concerning decisions which has been noted for years, Farny in particular points to the need for empirical goal research in iba (see Farny [1970], 42 ; Kaluza [1979], 2-11).

Since there are no hypothesis on the goals of insurance companies that are backed up by empirical studies, we have made such a study with the help of questionnaires and, additionally, structured interviews (see Kaluza [1979], 573-587).

The discussion of the question which goals should be considered to be fundamental in the theory of iba, seems to be of some importance for two reasons. We assume that the subject area general business administration (see e.g. Heinen [1980], 26-28) and the more specialized iba (see e.g. Farny [1977 a], 9-21) must help to solve two basic tasks : (1) to shape (define) and (2) to explain. Therefore one must examine, on the basis of which goals for insurance companies one should procede in further ibaresearch, so as to be able to develop proposals for action to shape the course of events pertaining to an insurance company. The development of such proposals for action, however, demands that one knows which goals are important to insurance companies. Within the framework of explaining problems pertaining to the insurance business, it is also important to know something about the goals of insurance companies. Only if one is aware of the options that are available and the goals that are being sought is one able to make prognoses concerning the course of action that should be taken and therefore to explain certain actions (see e.g. Cyert/March [1963], $304+305$ ).

Let us present the individual steps that were taken in our analysis. Our efforts to describe the present level of knowledge in empirical goal research has shown that business enterprises usually strive to attain a number of goals which are organized into a sort of configuration of goals. If this, however, is the case, it will no longer suffice to simply look to individual organizational goals. Rather we must consider systems of goals (to the formal structure of goal systems see Figure 2) to be the objects of empirical goal research. Therefore the following questions will be examined :

- Which systems of goals are actually being used?

(Analysis concerning existence : Describe the systems of goals.)

- How and why do certain systems of goals take on a certain form ?

(Contingency analysis : Systems of goals as variables that are being influenced.)

- What are the consequences of certain systems of goals taking on certain forms? (Analysis concerning effects : Systems of goals as variables that exert influences.)

To answer these three questions we differentiate between the following steps : the analysis concerning existence, the contingency analysis, and the analysis concerning effects. 
In our research we have primarily dealt with the analysis concerning existence. In other words we have asked ourselves the question : how can one describe a system of goals, and how can one organize the systems of goals that one encounters in empirical research?

\subsection{Analysis concerning existence of goal systems}

Two of the four tasks included in an analysis concerning existence of goal systems are (1) to find out what the organizational goals are and (2) to analyse these goals.

With a closed comprehensive questionnaire (containing 10 pages with 14 questions and further sub-questions) we requested information from the top management of all 87 German insurance companies that insure automobiles. 62 insurance companies $(=71.3$ per cent) responded, and 41 insurance companies $(=47.1$ per cent) returned the questionnaire after having filled it out, in some cases accompanied by long letters. ${ }^{9}$

The members of top management were asked to determine the six most important goals from a total of 13 listed goals and to rate these according to their relative importance. Furthermore, they were asked to underline those goals which in their opinion were irrelevant (in particular the goals "image and power", "ethical and social principles", " maintenance of nominal capital " were stressed).

In the following Table 1 we have organized the most prominent goals according to their importance (the goal on the first rank got 6 points, the goal on the second rank 5 points ..., and the goal on the sixth rank got 1 point).

\begin{tabular}{|l|l|}
\hline Goal content & Mean \\
\hline 1. Security of the firm & 4.21 \\
2. Satisfy the demand for insurance & 3.00 \\
3. Cover costs & 2.56 \\
4. Increase sales and assets & 2.51 \\
5. Profit increase & 2.49 \\
6. Maintain and expand the size of the firm & 2.33 \\
7. Maintain solvency & 1.72 \\
\hline
\end{tabular}

Table 1 : Statistics of the seven important goals of insurance companies 10

In order to improve and to confirm the validity as well as reliability of our research, we have additionally carried out structured oral interviews.

9 For detailed data see Kaluza [1979], 573-587. See for the questionnaire ibidem, A1-A3. 10 For a detailed information see Kaluza [1979], 610-654, spec. table 52.16, 622. 
Security of the firm is by far the most prominent goal for an insurance company. Both the insurance industry and the literature on iba consider this goal to be of significant importance. This importance seems logical when one looks at the nature of the insurance business, since to provide insurance cover means that you give other business entities security. The special position of the goal security within the goal systems of insurance companies is also made plain by the fact that the Federal Supervisory Office for Insurance Companies (abbreviated BAV) demands and makes sure that security is considered to be a goal by insurance companies.

It is interesting to note that the goal maintain solvency is considered to be of only secondary importance. To explain this fact it is necessary to look at the financial situation in which insurance companies usually find themselves. This situation is characterized by the fact that the receipts (premiums) usually must be paid in advance and therefore flow in at the beginning of a period, whereas the majority of expenses are due later. An insurance company therefore is mostly not in danger of losing its solvency, but rather must take care to minimize the amount of liquid assets that are not invested profitably.

The importance of the following goals is lower than that of the goal security of the firm and higher than that of the goal maintain solvency: Satisfy the demand for insurance; cover costs; increase sales and assets; increase profits; maintain and expand the size of the firm. There can be two reasons for this :

1. these goals are considered to be of secondary importance and their attainment is subordinate to ensuring that the goal security of the firm is reached;

2. they are of different importance to different insurance companies.

This is indicated by relatively high variances.

We will follow up both of these hypotheses when we subsequently make a contingency analysis.

We would now like to discuss the analysis of goal systems and complete the analysis concerning existence. In other words, we would like (3) to develop certain types of goal systems in order to be able to classify certain groups of goal systems and to then (4) analyse these types of goal systems.

Before proceeding any further in this direction we must answer the question : Is it possible to analyse entire goal systems? Usually each goal is analysed separately.

According to Witte (see Witte [1972 a], 24) recent empirical goal research has shown that in reality two goal systems are practically never identical.

However, to make the development of a theory possible one must, in our opinion, develop certain types of goal systems which can up to a certain point neglect complexities of reality. Therefore we will try to establish which systems of goals are similar and which are not. We intend to solve this problem with the help of cluster analysis. Cluster analysis, which is also referred to as empirical classification, is one of the methods to analyse problems involving several variables. These methods divide a given number of objects, which can be described with the help of $m$ criteria, into 
disjunct groups, which are called classes (clusters), in such a way that the objects of one group are as similar as possible concerning all $m$ criteria. At the same time objects that belong to different groups should be as different as possible (see e.g. Everitt [1974]; Vogel [1975]). We have conducted the cluster analysis with the procedure Hierarchy by Wishart (see Wishart [1978]). It is an agglomerative, noniterative, hierarchical clustering method. The measurement of similarity and distance between the individual goal systems has been done with the Euclidean distances. The results of clustering techniques are presented in the form of a dendrogram, which is a two-dimensional diagram illustrating the fusions which have been made at each successive level. The completion of our cluster analysis (for detailed information see Kaluza [1979], 682-697 and the literature referred ; for a dendogram see ibidem, 688) has resulted in our getting four clusters with the following profiles.

In cluster I the goals increase profits and maintain and expand the size of the firm were judged to be most important. The goal increase sales usually followed suit. Surprisingly the goal security of the firm appeared only in 4th place (in 5 of 6 cases). Consequently, cluster I describes an insurance company that is oriented towards profits and expansion.

Cluster II does not have a clearly dominating goal. The goals increase profits, satisfy the demand for insurance and others are judged to be the most important.

Cluster III is easily described. The goal satisfy the demand for insurance is considered the most important goal in all cases. Possibly this is an expression of the principles that have led to the founding of insurance companies in earlier times, such as the principles of taking care of oneself (mutual insurance companies - Versicherungsvereine auf Gegenseitigkeit, abbreviated $\mathrm{VVaG}$ ) and of taking care of others on a non-profit basis (public insurance companies - öffentlich-rechtliche Versicherungsunternehmen, abbreviated ör VU).

Cluster IV describes another stereotype of the insurance industry. Security of the firm is more important than any other consideration. This completely fits the image of the insurance entrepreneur who stresses security and is very sensitive to risk taking. We can therefore conclude that the combining of goals to form goal systems is a problem that has been researched only to a limited extent and that has considerable potential concerning the number of solutions that are possible.

Up to this point we have only organized the systems of goals into certain types which enable us to stress important aspects of our field of study and at the same time simplify it.

\subsection{Contingency analysis of goal systems}

Let us determine which factors are responsible for making types of systems dominant. In the course of our study we have condensed the 7 important goals of our questionnaire (see Figure 1) into 3 factors by doing a factor analysis. We have conducted the factor analysis with the subprogram Factor by Kim (see Kim [1975], 
468-514). After the preparation of the correlation matrix we have carried out the extraction of the initial factors with the method PA 2 (principal factoring with iteration) and the rotation with the "orthogonal rotation varimax" (see Kim [1975], 480-485 ; Kaluza [1979], 669-681).

As a starting-out hypothesis we have postulated that the following main goals are contingent on the existence of a certain legal framework for an organization :

legal framework

AG (joint-stock insurance companies)

ör VU (public insurance companies)

VVaG (mutual insurance companies) main goals

success (increase profits) security, provide insurance security, provide insurance

According to this hypothesis percentagewise more AG's should be in cluster I, wherease more VVaG and ör VU should be in Clusters III and IV. Cluster II is rather heterogenous concerning the different kinds of goal systems. One can postulate for this cluster that there should be a small predominance of AG's, since the goal increase profits is usually thought to be relatively important (see Kaluza [1979], 696 ; Kaluza [1982 a], $8+9$ ).

To test these assumptions, we would like to refer to the following Table 2.

\begin{tabular}{|l|rrrr|r|}
\hline $\begin{array}{l}\text { Legal } \\
\text { framework }\end{array}$ & I & II & III & IV & sum \\
\hline AG & & & & & \\
ör VU & 6 & 9 & 4 & 4 & 23 \\
VVaG & - & 1 & 2 & 3 & 6 \\
\hline sum : & - & 1 & 4 & 5 & 10 \\
\hline
\end{tabular}

Table 2 : Distribution of the different $K-V U$ on the clusters $I$ to IV

To give an appropriate picture concerning the percentages we will combine the ör VU and the VVaG into one group as well as clusters I and II and III and IV in accordance to our assumptions.

This will result in the following Table 3 : 


\begin{tabular}{|l|rrrr|cc|}
\hline $\begin{array}{l}\text { Legal } \\
\text { framework }\end{array}$ & I $+\mathrm{II}$ & $\mathrm{III}+\mathrm{IV}$ & \multicolumn{2}{|c|}{ sum } \\
\hline $\begin{array}{l}\mathrm{AG} \\
\text { ör } \mathrm{VU}+\mathrm{VVaG}\end{array}$ & & & & & & \\
\hline sum & $15 *$ & $65.2 \%$ & 8 & $34.8 \%$ & 23 & $100 \%$ \\
\hline
\end{tabular}

Table 3 : Summary of the description of clusters $I+I I$ and III $+I V$

* = absolute frequency.

Because of the limited number of cases used to develop this table it is not possible to conduct a chi-square independence test. Since the individual percentages, however, strongly point towards this hypothesis, we think it would be wise to further work with this hypothesis. Our next step will be to make a brief analysis concerning effects of goal systems.

\subsection{Analysis concerning effects of goal systems}

Since it was not possible to conduct an analysis concerning effect of goal systems on the basis of our data, we utilized data compiled by Witte and his associates ${ }^{11}$ to examine certain aspects involving decision goals. In this context we shall examine the consequences that would occur when a certain decision problem has to be solved, if the decision makers in a firm have different goal systems.

In our concrete case we wanted to know what results, if any, the goal systems of insurance companies that so stress security would appear in comparison to firms in other industries.

In the studies the decision processes evolved around the procurement of EDPequipment. Hauschildt (see Hauschildt [1977], 209) drew the following general conclusions :

In the decision process which is involved in buying a firm's first EDPequipment the decision goals are independent of the type of product that the firm produces.

In the test conducted by us we could not detect any significant differences between the goal-object-relationships in different industries. This verifies Hauschildt's more

11 For detailed information on these studies see Witte [1972 a] ; Witte [1972 b], 156-182. 
general statement, that the decision goals in a decision process concerned with the procurement of EDP-equipment are independent of the industry involved. We could also not detect any significant differences between the decision processes in insurance companies and in business enterprises engaged in other industries concerning the attributes of specific goals. The results of a direct comparison between insurance companies and banks, however, proved to be interesting. In the decision processes in insurance companies considerably more goals were articulated than in the decision processes in banks. Especially cost-benefit considerations were stressed more often in insurance companies than in banks. The differences could possibly be explained by the conditions that govern the use of EDP-equipment in these two industries. In insurance companies EDP-equipment was used especially to increase productivity (see Kaluza [1972], 119 ; Farny [1977 b], 171-176), meaning costs were to be lowered. Banks, on the other hand, used EDP-equipment to improve their capabilities to transfer money and to provide services at their counters. Profitability was to be increased indirectly by providing services that demanded certain advanced equipment.

Furthermore, we have examined the measuring of goal attainment. In accordance with Hauschildt one can operationalize the attributes of goals by judging the measuring of goal attainment. One can differentiate between nominal, ordinal and cardinal measures of goal attainment.

One could not see any significant differences between insurance companies and the business firms of all the other industries when comparing the measures of goal attainment pertaining to the decision processes. We could, however, discern differences between insurance companies and banks concerning the articulation of the cardinally and ordinally scaled measures of goal attainment. Cardinal measures of goal attainment were particularly often articulated in insurance companies compared to banks (see Kaluza [1979], 564). An additional analysis (see Kaluza [1982 b] concerning effects of goal systems in insurance companies will be made on the basis of data that is being collected at the moment for the research project Reinsurance decisions in direct-writing companies (see Helten [1981]) and on the basis of data that is being collected for the research project Computer-based office systems / office communication (see Reichwald et al [1982]).

\section{Conciusion}

Let us briefly summarize our findings of empirical research of goal systems in insurance companies and mention some of the resulting theoretical and practical consequences.

(1) The important rank of the goal security of the firm in the goal system of insurance companies has been empirically proven by us. There are no differences within the three legal frameworks.

(2) However, concerning the secondary goals, we could find considerable differences.

(3) As a methodological result we found out that the analysis of goal systems is a demanding task in goal research and that the cluster analysis technique is a suitable method for analysing and standardizing goal systems. 
In our paper we have shown the necessity of doing further research in the area of empirical goal research with regard to the changes in goal systems in the lapse of time (longitudinal analyses and panel surveys) and the dynamic aspects of the goal formation process. In this connection it must be borne in mind that goal formation is not only a process of conflict resolution (Cyert/March), but it is also a cognitive process.

Because of the importance of the goal security of the firm there are theoretical and practical consequences.

As a theoretical consequence for further empirical research an analysis of effects of goal systems must be carried out.

Aspects which have to be further investigated are as follows :

How is the goal security of the firm reflected in the business projects of the insurance companies?

How is this security goal embodied in and favoured by the goal system of the insurance companies?

Furthermore all persons involved in the goal formation process have to be interviewed.

As a practical consequence we must ask how the security goal can actually be introduced as a strategy of risk management in the course of a goal control. Therefore the specification of this goal by means of a negative goal catalogue is likely to present itself.

How fuzzy can the goal security of the firm be in order to allow a certain line of actions?

Do our explanations suffice in order to make shape proposals for the control of goal formation processes?

It may finally be concluded that it is the basic task of empirical goal research to define the elements of an expressive general multivariable goal system of insurance companies.

\section{REFERENCES}

CYERT, R. M., and MARCH, J.G. [1963] : A Behavioral Theory of the Firm, Prentice-Hall, Englewood Cliffs (New Jersey).

EVERITT, B. [1974] : Cluster Analysis, Heinemann Educational Books, London - Edinburgh.

FARNY, D. [1969] : "Grundfragen einer theoretischen Versicherungsbetriebslehre", in Wirtschaft und Recht der Versicherung - Festschrift für Paul Braeß zum 66. Geburtstag, FARNY, D. (Ed.), Verlag Versicherungswirtschaft, Karlsruhe, 27-72.

FARNY, D. [1970] : "Wenig Anregung für rationale Betriebsführung in der Praxis", Wirtschaftswoche, 24 (45/1970), 42.

FARNY, D. [1977 a] : "Ansätze einer betriebswirtschaftlichen Theorie des Versicherungsunternehmens ", The Geneva Papers on Risk and Insurance, 5 (February 1977), 9-21. 
FARNY, D. [1977 b] : “Die Betriebskosten der Versicherungsuntemehmen - Gedanken zu den künftigen Problemen und ihrer Lösung", Versicherungswirtschaft, 32 (3/1977), 166-176.

GEMUNDEN, H. G. [1981] : Innovationsmarketing. Interaktionsbeziehungen zwischen Hersteller und Verwender innovativer Investitionsgüter, J. C. B. Mohr (Paul Siebeck), Tübingen.

GRUN, O. [1976] : “Zielbildung, Prozesse der", in Handwörterbuch der Betriebswirtschaft, GROCHLA, E., and WITTMANN, W. (Eds.), 4th ed., vol. 3. C. E. Poeschel, Stuttgart, 4719-4730.

HAUSCHILDT, J. [1970] : “Zur Artikulation von Unternehmenszielen”, Zeitschrift für betriebswirtschaftliche Forschung, 22 (June 1970), 545-559.

HAUSCHILDT, J. [1973] : “Die Struktur von Zielen in Entscheidungsprozessen - Bericht aus einem empirischen Forschungsprojekt", Zeitschrift für betriebswirtschaftliche Forschung, 25 (November 1973), 709-738.

HAUSCHILDT, J. [1976] : “Zielbildung - ein heuristischer Prozess", Zeitschrift für Betriebswirtschaft, 46 (4/5-1976), 327-340.

HAUSCHILDT, J. [1977] : Entscheidungsziele. Zielbildung in innovativen Entscheidungsprozessen: theoretische Ansätze und empirische Prüfung, J.C.B. Mohr (Paul Siebeck), Tübingen.

HAUSCHILDT, J., and HAMEL, W. [1978] : “Empirical goal research - on its way into a blind alley", Theory and Decision, 9 (2/1978), 173-186.

HEINEN, E [1971] : Grundlagen betriebswirtschaftlicher Entscheidungen - Das Zielsystem der Unternehmung, 2nd ed., Gabler, Wiesbaden.

HEINEN, E. [1980] : Einführung in die Betriebswirtschaftslehre, 7th rev. ed., Gabler, Wiesbaden.

HELTEN, E. [1981] : “ Konzeption einer verhaltenswissenschaftlich orientierten Theorie der Rückversicherungsentscheidungen von Erstversicherungsunternehmen ", in Geld, Banken und Versicherungen, GOOPPL, H., and HENN, R. (Eds.), Athenäum, Königstein/Ts., vol. 2, 780-791.

HÖLLER, H. [1978]: Verhaltenswirkungen betrieblicher Planungs- und Kontrollsysteme, Florentz, München.

KALUZA, B. [1972]: Spieltheoretische Modelle und ihre Anwendungsmöglichkeiten im Versicherungswesen, Duncker \& Humblot, Berlin.

KALUZA, B. [1979] : Entscheidungsprozesse und empirische Zielforschung in Versicherungsunternehmen, Verlag Versicherungswirtschaft, Karlsruhe.

KALUZA, B. [1982 a] : "Entscheidungsziele und Unternehmungsziele von Versicherungsunternehmen ", in Operations Research Proceedings 1981, DGOR Papers of the Annual Meeting 1981, Springer, Berlin, Heidelberg, New York, 142-151.

KALUZA, B. [1982 b] : “Zielbeziehungs- und Zielsystemanalyse in Versicherungsunternehmen ", Zeitschrift für die gesamte Versicherungswissenschaft, 72 (4/1982) (in preparation).

KARTEN, W. [1976] : “Versicherungsbetriebslehre", in Handwörterbuch der Betriebswirtschaft, GROCHLA, E., and WITTMANN, W. (Eds.), 4th ed., vol. 3, C. E. Poeschel, Stuttgart, 4246-4255.

KIM, J.-O. [1975] : “Factor Analysis", chapter 24, in SPSS - Statistical Package for the Social Sciences, NIE, N. H. et al (Eds.), 2nd ed. Mc Graw-Hill, New York, St. Louis, etc., 468-514.

KUPSCH, P. [1979] : Unternehmungsziele, Gustav Fischer, Stuttgart-New York.

LATHAM, G. P., and YUKL, G. A. [1975] : "A review of research on the application of goal setting in organizations ", Academy of Management Journal, 18 (4/1975), 824-845. 
LERCHNER, H. [1975] : Zielforschung in Unternehmungen, Gabler, Wiesbaden.

REICHWALD, R., et al [1982] : Acceptance of a Computer-Based Office System - Framework and Methods for a Field Project (in preparation).

SCHULZ, E. [1979] : “ Uber die Nutzanwendung des Management by Objectives ", Zeitschrift für Versicherungswesen, 30 (3/1979), 72-75.

STREBEL, H. [1981] : “Zielsysteme und Zielforschung ”, Die Betriebswirtschaft, 41 (3/1981), 457-475.

SZYPERSKI, N. [1975] : “Geldwertstabilität aus der Sicht privater Unternehmungen situative und strukturelle Aspekte", in SCHNEIDER, H.K., WITTMANN, W., and WURGLER, H. (Eds.), Stabilisierungspolitik in der Marktwirtschaft, Duncker \& Humblot, Berlin, 247-272.

TOSY, H., and CAROLL, St. J. [1973] : “Improving management by objectives : A diagnostic change program ", California Management Review, 16 (2/1973), 57-66.

TOSY, H., et al [1976]: "How real are changes induced by management by objectives", Administrative Science Quarterly, 21 (June 1976), 276-306.

VOGEL, F. [1975] : Probleme und Verfahren der numerischen Klassifikation, Vandenhoeck \& Ruprecht, Göttingen.

WARNER, W. K., and HAVENS, A. E. [1967] : “Goal displacement and the intangibility of organizational goals", Administrative Science Quarterly, 12 (June 1967), 539-555.

WISHART, D. [1978] : Clustan. User Manual, 3rd ed., Program Library Unit, Edinburgh University, Edinburgh.

WITTE, E. (Ed.) [1972 a] : Das Informationsverhalten in Entscheidungsprozessen, J.C. B. Mohr (Paul Siebeck), Tübingen.

WITTE, E. [1972 b] : " Field research on complex decision-making processes - The Phase Theorem ", International Studies of Management and Organization, 11 (2/Summer 1972), 156-182.

WITTE, E. [1974] : “Empirische Forschung in der Betriebswirtschaftslehre ", in Handwörterbuch der Betriebswirtschaft, GROCHLA, E., and WITTMANN, W. (Eds.), 4th ed., vol. 1, C. E. Poeschel, Stuttgart, 1264-1281. 